\title{
Guest editors' notes: Special issue on qualitative research support
}

Welcome to the second issue of Volume 43 of the IASSIST Quarterly (IQ 43:2, 2019). Four papers are presented in this issue on qualitative research support. This special issue arises from conversations in the Qualitative Social Science and Humanities Data Interest Group (QSSHDIG) at IASSIST about how best to support qualitative researchers. This group was founded in 2016 to explore the challenges and opportunities facing data professionals in the social sciences and humanities, and has focused on using, reusing, sharing, and archiving of qualitative, textual, and other non-numeric data.

In 'Annotation for transparent inquiry (ATI),' Sebastian Karcher and Nic Weber present their work on a new approach to transparency in qualitative research by the same name, which they have been exploring at the Qualitative Data Repository at the University of Syracuse, New York. As one solution to the problem of 'showing one's work' in qualitative research, ATI allows researchers to link final reports back to the underlying qualitative and textual data used to support a claim. Using the example of Hypothes.is, they discuss the positives and negatives of ATI, particularly the amount of time required to annotate a qualitative article effectively and technical limitations in widespread web display.

The next article highlights how archived materials can be re-used by qualitative researchers and used to build their arguments. In 'Research driven approaches to archival discovery,' Diana Marsh examines what qualitative researchers need from the collections at the National Anthropological Archives in the United States, in order to improve archival discovery for those not as accustomed to working in the archives.

In 'Bringing method to the madness,' Mandy Swygart-Hobaugh, Leader of the Research Data Services Team at the Georgia State University Library, outlines a project created to bridge the gap between training researchers to use qualitative data software and training them in qualitative methods. Her answer has been a collaborative workshop with a sociology professor who provides a methodological framework while she applies those principles to a project in NVivo. These successful workshops have helped to encourage researchers to consider qualitative methods while at the same time promoting the use of CAQDAS software.

Jonathan Cain, Liz Cooper, Sarah DeMott, and Alesia Montgomery in their article 'Where QDA is hiding?' draw on a study originally conducted for QSSHDIG to create a list of qualitative data services in libraries. When they realized that finding these services was quite difficult, they expanded the study to examine the discoverability of library sites supporting QDA. This study of 95 academic library websites provides insight into the issues of finding and accessing library websites that support the full range of qualitative research needs. They also outline the key characteristics of websites that provide more accessible access to qualitative data services.

We thank our authors for participating in this special issue and providing their insights on qualitative data and research. If you are interested in issues related to qualitative research, then please join the Qualitative Social Sciences and Humanities Data Interest Group. Starting with IASSIST 2019 in Australia, our interest group has a new leadership team with two of our authors, Sebastian Karcher and Alesia Montgomery, taking over as co-conveners. We are certain that they would love to hear your ideas for the group, and we look forward to working with the qualitative data community more in the future.

1/2 Kellam, Lynda; Emmelhainz, Celia (2019) Guest editors' notes: Special issue on qualitative research support, IASSIST Quarterly 43(2), pp. 1-2. DOI: https://doi.org/10.29173/iq954 
Lynda Kellam, Cornell Institute for Social \& Economic Research

Celia Emmelhainz, University of California, Berkeley

2/2 Kellam, Lynda; Emmelhainz, Celia (2019) Guest editors' notes: Special issue on qualitative research support, IASSIST Quarterly 43(2), pp. 1-2. DOI: https://doi.org/10.29173/iq954 